\title{
Self-Assembling of Cytosine Nucleoside Into Triply-Bound Dimers in Acid Media. A Comprehensive Evaluation of Proton-Bound Pyrimidine Nucleosides by Electrospray Tandem Mass Spectrometry, X-rays Diffractometry, and Theoretical Calculations
}

\author{
Donatella Armentano, Giovanni De Munno, Leonardo Di Donna, \\ and Giovanni Sindona \\ Dipartimento di Chimica, Università della Calabria, Arcavacata di Rende (CS), Italy

\section{Gianluca Giorgi and Laura Salvini} \\ Dipartimento di Chimica and Centro Interdipartimentale di Analisi e Determinazioni Strutturali, Università di \\ Siena, Siena, Italy
}

\begin{abstract}
Electrospray tandem mass spectrometry (ESI-MS/MS) is used to evaluate the assembling of cytosine and thymine nucleosides in the gas phase, through the formation of hydrogen bonded supermolecules. Mixtures of cytidine analogues and homologues deliver in the gas phase proton-bound heterodimers stabilized by multiple interactions, as proven by the kinetics of their dissociation into the corresponding protonated monomers. Theoretical calculations, performed on initial structures of methylcytosine homodimers available in the literature, converged to a minimized structure whereby the two pyrimidine rings interact through the formation of three hydrogen bonds of similar energy. The crystallographic data here reported show the equivalency of the two interacting pyrimidines which is attributable to the presence of an inversion center. Thymine and uracil pyrimidyl nucleosides form, by ESI, gaseous proton-bound dimers. The kinetic of their dissociation into the related protonated monomers shows that the nucleobases are weekly interacting through a single hydrogen bond. The minimized structure of the protonated heterodimer formed by thymine and N-1-methylthymine confirmed the existence of mainly one hydrogen bond which links the two nucleobases through the $\mathrm{O} 4$ oxygens. No crystallographic data exists on thymine proton-bound species, nor have we been able to obtain these aggregates in the solid phase. The gaseous phase, under high vacuum conditions, seems therefore a suitable environment where vanishing structures produced by ESI can be studied with a good degree of approximation. (J Am Soc Mass Spectrom 2004, 15, 268-279) (C 2004 American Society for Mass Spectrometry
\end{abstract}

$\mathrm{M}$ ulti-stranded nucleic acid structures [1] are formed by non B-DNA assembling of polynucleotides which may have specific functional roles in vivo [2,3] and may be used as therapeutics [4-6].

A strong impulse to the research in this field was presented by the discovery that atypical DNA conformations play a role in expansions of repeated trinucleotide motifs which cause a multiplicity of severe human diseases $[7,8]$. These pathological expansions

Published online January 10, 2004

Address reprint requests to Dr. G. Sindona, Dipartimento di Chimica, Università della Calabria, via P. Bucci, cubo 15/C, I-87030 Arcavacata di Rende (CS), Italy. E-mail: sindona@unical.it include the $(\mathrm{CCG})_{\mathrm{n}} \cdot(\mathrm{CGG})_{\mathrm{n}}$ repeats, related to the fragile- $X$ syndrome, the $(C A G)_{n} \cdot(C T G)_{n}$ repeats related to Kennedy's and Huntington's disease, spinocerebellar ataxia and myotonic dystrophy, and the (GAA) $\cdot(\text { TTC })_{n}$ repeats associated with Friedrich's ataxia [9-12].

Three- and four-stranded DNA structures have been elucidated either by NMR spectroscopy or by X-ray crystallography. The first NMR studies of DNA triplexes confirmed the proposed Hoogsteen and WatsonCrick pairing for $\mathrm{T} \cdot \mathrm{A} \cdot \mathrm{T}$ and $\mathrm{C}^{+} \cdot \mathrm{G} \cdot \mathrm{C}$ triplets [13-15]. Furthermore, a recently-discovered new class of DNA structures derived from a considerable asymmetry in distribution of purines and pyrimidines between the complementary strands includes non-Watson-Crick base pairing and is stabilized by acid $\mathrm{pH}$. One of them, 


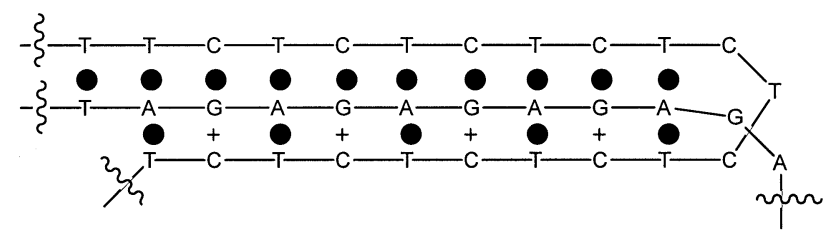

Figure 1. $\mathrm{pH}$ dependent Hoogsteen base pairing in the triply heliced $\mathrm{H}$ structure of DNA (adapted from reference [1b]).

the $H$ structure, corresponds to a triplex arrangement whereby $\mathrm{pH}$ dependent Hoogsteen base pairing such as $\mathrm{C}^{+} \cdot \mathrm{G}$ are in operation (Figure 1 ).

Another $\mathrm{pH}$ dependent assembling is represented by the $(\mathrm{C}, \mathrm{A})$ hairpin structure. This arrangement develops when $C$ rich and $A$ rich telomers interact. In the typical $\left(\mathrm{G}_{4} \mathrm{~T}_{2}\right)-\left(\mathrm{A}_{2} \mathrm{C}_{4}\right)[16]$ motif, stable $\mathrm{C}^{+} \cdot \mathrm{C}$ and $\mathrm{A}^{+} \cdot \mathrm{A}$ pairs are formed between both parallel and anti-parallel strands, under acidic conditions. In this particular case the $\mathrm{C}^{+} \cdot \mathrm{C}$ arrangement may arise by an anti-parallel base pairing in which the N3 of one cytosine is protonated and two hydrogen bonds occur between the bases.

Among all the known motifs characterizing multiply stranded DNA polymers the presence of protonated nucleobases, such as cytosine, deserve a particular interest. The interest in multiple interacting nucleic acid molecules is, however, not limited to biochemical applications.

Molecular devices based on linear arrays of interacting nucleic acids and heterocyclic molecules depend, in fact, on the establishment of multiple hydrogen bonded systems [17].

Clustering of short oligonucleotides has also been observed in the gas phase since the pioneering application of mass-spectrometric desorption ionization methods [18].

The formation of gaseous supramolecules has become more accessible after the appearance of electrospray ionization (ESI) methods [19]. Accordingly, the observation that a good correlation is shown by ESI and solutionphase data has, very recently, prompted the investigation of nucleoside self-clustering in the gas phase [20].

The formation of gaseous proton-bound heterodimers between nucleosides, nucleotides, and reference amines represents a unique tool for the evaluation, by the kinetic method [21], of nucleic acid proton affinities (PA) [22, 23]. It was recently proven that similar data could also be provided by the unimolecular dissociations of proton-bound nucleoside dimers [24].

Tandem mass spectrometry represents the only reliable means for the evaluation of nucleoside PA, as proven by the number of citation of the original works [22] and by the fact that the available compilation of nucleoside PAs is based on the thermodynamic data obtained by this approach [25].

In the next sections, the existence in the gas phase of triply hydrogen-bonded cytidines will be proven by applying the kinetic methods, in the classic approach [21], with references to the calculations performed on model protonated cytosine dimers and to the solid phase structural data collected from crystals of protonated N-1-methylcytosine homodimers. Self-assembling of thymine nucleosides will be also presented.

\section{Experimental}

\section{Materials}

Cytidine (C), 2'-deoxycytidine $\left(2^{\prime}-\mathrm{dC}\right), 3^{\prime}$-deoxycytidine $\left(3^{\prime}\right.$-dC), 2', $3^{\prime}$-dideoxycytidine $\left(2^{\prime}, 3^{\prime}\right.$-ddC), $2^{\prime}, 5^{\prime}$ dideoxycytidine $\left(2^{\prime}, 5^{\prime}\right.$-ddC), thymidine $(\mathrm{T}), 3^{\prime}$-deoxythymidine $\left(3^{\prime}-\mathrm{dT}\right), 5^{\prime}$-deoxythymidine (5'-dT), 5-methyl Uridine (5-MeU), $N$-1-Methylcytosine and calcium perchlorate were commercially available. Compound $\mathbf{1}$ have been obtained by slow evaporation, at room temperature, of an aqueous solution containing calcium perchlorate and N-1-Methylcytosine. Salt hydrolysis provides the acid media for nucleobase protonation.

\section{Instrumentation and Methods}

The electrospray ionization (ESI) experiments were carried out in a hybrid Q-Star Pulsar-i (PE Sciex, Toronto, Canada) mass spectrometer equipped with an ion spray ionization source. Proton-bound dimers were generated by direct infusion $(5 \mu \mathrm{L} / \mathrm{min})$ of a solution containing the appropriate nucleoside (4-12) and the given reference compound $(10 \mathrm{pmol} / \mu \mathrm{L}$, dissolved in solution $0.1 \%$ acetic acid, methanol/water $50 / 50$ ) at the optimum ion spray voltage of $4800 \mathrm{~V}$. The nitrogen gas flow was set at 20 psi and the declustering and the focusing potentials were kept at 40 and $130 \mathrm{~V}$ relative to ground, respectively. MS/MS experiments were performed in the collision cell $q$ on the isotopically pure $\left({ }^{12} \mathrm{C}\right)$ peak of the selected precursor ions by keeping the first quadrupole analyzer at $19 \mathrm{~V}$ relative to ground and operating at unit resolution, and scanning the time-offlight (TOF) analyzer. The collisional induced dissociations (CID) measurements, at fixed collision gas pressure, were performed at the instrumental parameters CAD 1 , which corresponds to $9^{*} 10^{-4}$ torr and $6.26^{*} 10^{14}$ molecules $/ \mathrm{cm}^{2}$ gas thickness. All the acquisitions were averaged over 60 scans at a TOF resolving power of 8000 with a standard deviation of $0.01 \mathrm{cps}$. The CID measurements were performed at the $q$ voltages of 4,6 , 8, and $10 \mathrm{eV}$, corresponding to the collision energy calculated from $\mathrm{E}_{\mathrm{cm}}=\mathrm{E}_{\mathrm{lab}}(\mathrm{m} /[\mathrm{m}+\mathrm{M}])$.

Theoretical $\mathrm{ab}$ initio calculations were performed on proton bound dimers of cytosine and thymine. A proton was added on the most probable site of protonation of one of the two molecules of the monocharged dimers. In order to mime the $\mathrm{N}$-glycosidic bond, a methyl group, or in some cases an isopropyl group, were introduced at N1. Different structures, differing in mutual base orientations, were considered as starting geometries.

All the initial structures of the proton bound dimers were fully optimized at the Hartree-Fock (HF) level. The 6-31G(d) basis set, which gives a good description of hydrogen bonded complexes [26-28], was used. The cal- 
Table 1. Crystallographic data for [(1-MeCytH) $\cdot(1-\mathrm{MeCyt})](\mathrm{ClO} 4)(1)$

\begin{tabular}{|c|c|c|}
\hline Empirical formula & $\mathrm{C} 10 \mathrm{H} 15 \mathrm{Cl}$ N6 O6 & \\
\hline Formula weight & 350.73 & \\
\hline Temperature & $293(2) \mathrm{K}$ & \\
\hline Wavelength & $0.71073 \AA$ & \\
\hline Crystal system & Monoclinic & \\
\hline Space group & $\mathrm{P} 2(1) / \mathrm{n}$ & \\
\hline \multirow[t]{3}{*}{ Unit cell dimensions } & $a=7.380(3) \AA$ & $\alpha=90^{\circ}$ \\
\hline & $\mathrm{b}=8.732(2) \AA$ & $\beta=99.07(3)^{\circ}$ \\
\hline & $\mathrm{c}=12.117(4) \AA$ & $\gamma=90^{\circ}$ \\
\hline Volume & $771.1(4) \AA^{3}$ & \\
\hline Z & 2 & \\
\hline Density (calculated) & $1.511 \mathrm{Mg} / \mathrm{m}^{3}$ & \\
\hline Absorption coefficient & $0.289 \mathrm{~mm}^{-1}$ & \\
\hline$F(000)$ & 364 & \\
\hline Theta range for data collection & 2.89 to $27.06^{\circ}$. & \\
\hline Index ranges & $0 \Leftarrow \mathrm{h} \Leftarrow 9,0 \Leftarrow \mathrm{k} \Leftarrow 11,-15 \Leftarrow 1 \Leftarrow 15$ & \\
\hline Reflections collected & 1877 & \\
\hline Independent reflections & $1697[\mathrm{R}($ int $)=0.0312]$ & \\
\hline Completeness to theta $=27.06^{\circ}$ & $100.0 \%$ & \\
\hline Refinement method & Full-matrix least-squares on $\mathrm{F}^{2}$ & \\
\hline Data/restraints/parameters & $1697 / 0 / 124$ & \\
\hline Goodness-of-fit on F2 & 1.092 & \\
\hline Final $R$ indices $[I>2$ sigma $(I)]$ & $\mathrm{R} 1=0.0582, \mathrm{wR} 2=0.1574$ & \\
\hline $\mathrm{R}$ indices (all data) & $\mathrm{R} 1=0.0763, \mathrm{wR} 2=0.1701$ & \\
\hline Largest diff. peak and hole & 0.368 and -0.268 e. $\AA^{-3}$ & \\
\hline
\end{tabular}

culations were carried out with the Gaussian 98 suite of programs [29] implemented on a SGI Origin 3800 supercomputer at Cineca in Bologna.

The lowest energy geometries were confirmed as a minimum on the molecular potential energy surface by normal mode vibrational frequency calculations that produced all real frequencies.

The zero point energy corrections were also made.

Structural determination was performed on a crystal of 1 mounted on a Bruker R3m/V (Karlsruhe, Germany), automatic diffractometer and used for data collection. Diffraction data were collected at room temperature by using graphite-monochromated Mo-K $\alpha$ radiation $(\lambda=0.71073 \AA)$ with the $\omega$ - $2 \theta$ scan method. The unit cell parameters were determined from leastsquares refinement of the setting angles of 25 reflections in the $2 \theta$ range $15-30^{\circ}$. A summary of the crystallographic data and of the structure refinement is given in Table 1. Examination of two standard reflections, monitored after every 50 reflections, showed no sign of crystal deterioration. Lorentz-polarization and $\Psi$-scan absorption corrections [30] were applied to the intensity data. The maximum and minimum transmission factors were 0.728 and 0.913 .

The structure of $\mathbf{1}$ was solved by direct methods and subsequently completed by Fourier recycling. All nonhydrogen atoms were refined anisotropically except the oxygen atoms of the perchlorate moiety, which is disordered. The hydrogen atoms of the N-1-methylcytosine, except the hydrogen atom on N3 which was not observed in the $\Delta \mathrm{F}$ Fourier map, were set in calculated positions and refined as riding atoms with a common fixed isotropic thermal parameter. The final full-matrix least-squares re- finement on $\mathrm{F}^{2}$, minimizing the function $\mathrm{\Sigma}_{\mathrm{w}}\left(\left|\mathrm{F}_{\mathrm{o}}\right|-\left|\mathrm{F}_{\mathrm{c}}\right|\right)^{2}$, reached convergence with values of the discrepancy indices given in Table 1 . Solutions and refinements were performed with the SHELXTL NT system [31]. The final geometric calculations were carried out with the PARST program [32]. The drawings were performed using the XP utility of the SHELXTL NT system. Interatomic bond distances and angles for $\mathbf{1}$ are listed in Table 2.

CCDC reference number 206619 [1]; see http:// pubs.acs.org for crystallographic data in CIF format.

\section{Results and Discussion}

The formation of proton-bound homodimers of substituted nucleosides has been extensively investigated in the solid phase. The hemiprotonated N-1-methylcy-

Table 2. Selected Bond lengths $[\AA]$ and angles $\left[{ }^{\circ}\right]$ for $(1)$

\begin{tabular}{llll}
\hline $\mathrm{N}(1)-\mathrm{C}(6)$ & $1.358(4)$ & $\mathrm{C}(4)-\mathrm{C}(5)$ & $1.414(4)$ \\
$\mathrm{N}(1)-\mathrm{C}(2)$ & $1.375(4)$ & $\mathrm{C}(5)-\mathrm{C}(6)$ & $1.337(5)$ \\
$\mathrm{N}(1)-\mathrm{C}(1)$ & $1.474(4)$ & $\mathrm{Cl}(1)-\mathrm{O}(3)$ & $1.341(6)$ \\
$\mathrm{C}(2)-\mathrm{O}(2)$ & $1.229(3)$ & $\mathrm{Cl}(1)-\mathrm{O}(4)$ & $1.376(7)$ \\
$\mathrm{C}(2)-\mathrm{N}(3)$ & $1.369(3)$ & $\mathrm{Cl}(1)-\mathrm{O}(5)$ & $1.343(7)$ \\
$\mathrm{N}(3)-\mathrm{C}(4)$ & $1.350(3)$ & $\mathrm{Cl}(1)-\mathrm{O}(6)$ & $1.468(6)$ \\
$\mathrm{C}(4)-\mathrm{N}(4)$ & $1.317(4)$ & & \\
$\mathrm{C}(6)-\mathrm{N}(1)-\mathrm{C}(2)$ & $120.6(3)$ & $\mathrm{N}(3)-\mathrm{C}(4)-\mathrm{C}(5)$ & $119.4(3)$ \\
$\mathrm{C}(6)-\mathrm{N}(1)-\mathrm{C}(1)$ & $122.1(3)$ & $\mathrm{C}(6)-\mathrm{C}(5)-\mathrm{C}(4)$ & $117.9(3)$ \\
$\mathrm{C}(2)-\mathrm{N}(1)-\mathrm{C}(1)$ & $117.2(3)$ & $\mathrm{C}(5)-\mathrm{C}(6)-\mathrm{N}(1)$ & $122.3(3)$ \\
$\mathrm{O}(2)-\mathrm{C}(2)-\mathrm{N}(3)$ & $121.5(2)$ & $\mathrm{O}(3)-\mathrm{Cl}(1)-\mathrm{O}(5)$ & $117.3(6)$ \\
$\mathrm{O}(2)-\mathrm{C}(2)-\mathrm{N}(1)$ & $120.8(3)$ & $\mathrm{O}(3)-\mathrm{Cl}(1)-\mathrm{O}(4)$ & $107.8(6)$ \\
$\mathrm{N}(3)-\mathrm{C}(2)-\mathrm{N}(1)$ & $117.6(2)$ & $\mathrm{O}(5)-\mathrm{Cl}(1)-\mathrm{O}(4)$ & $113.5(6)$ \\
$\mathrm{C}(4)-\mathrm{N}(3)-\mathrm{C}(2)$ & $122.1(2)$ & $\mathrm{O}(3)-\mathrm{Cl}(1)-\mathrm{O}(6)$ & $105.2(4)$ \\
$\mathrm{N}(4)-\mathrm{C}(4)-\mathrm{N}(3)$ & $118.2(2)$ & $\mathrm{O}(5)-\mathrm{Cl}(1)-\mathrm{O}(6)$ & $105.6(6)$ \\
$\mathrm{N}(4)-\mathrm{C}(4)-\mathrm{C}(5)$ & $122.4(3)$ & $\mathrm{O}(4)-\mathrm{Cl}(1)-\mathrm{O}(6)$ & $106.5(5)$ \\
\hline
\end{tabular}




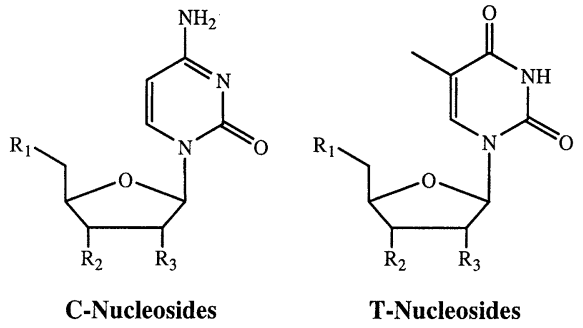

\begin{tabular}{lll}
\hline & Wild-type and modified nucleosides & PA (Kcal/mol) \\
\hline $\mathbf{4}$ & $\mathrm{R} 1=\mathrm{R} 2=\mathrm{R} 3=\mathrm{OH}$; Cytidine (C) & 234.80 \\
$\mathbf{5}$ & $\mathrm{R} 1=\mathrm{R} 2=\mathrm{OH}, \mathrm{R} 3=\mathrm{H} ; 2^{\prime}$-deoxycytidine $\left(2^{\prime}-\mathrm{dC}\right)$ & 236.20 \\
$\mathbf{6}$ & $\mathrm{R} 1=\mathrm{R} 3=\mathrm{OH}, \mathrm{R} 2=\mathrm{H} ; 3^{\prime}$-deoxycytidine(3'-dC) & 236.26 \\
$\mathbf{7}$ & $\mathrm{R} 2=\mathrm{R} 3=\mathrm{H}, \mathrm{R} 1=\mathrm{OH} ; 2^{\prime}, 3^{\prime}$-dideoxycytidine $\left(2^{\prime}, 3^{\prime}-\mathrm{dC}\right)$ & 237.60 \\
$\mathbf{8}$ & $\mathrm{R} 1=\mathrm{R} 3=\mathrm{H} ; \mathrm{R} 2=\mathrm{OH} ; 2^{\prime}, 5^{\prime}$-dideoxycytidine $\left(2^{\prime}, 5^{\prime}-\mathrm{dC}\right)$ & 234.69 \\
$\mathbf{9}$ & $\mathrm{R} 1=\mathrm{R} 2=\mathrm{R} 3=\mathrm{OH} ; 5-$-Methyluridine (5-MeU) & 226.00 \\
$\mathbf{1 0}$ & $\mathrm{R} 1=\mathrm{R} 2=\mathrm{OH}, \mathrm{R} 3=\mathrm{H} ;$ Thymidine (T) & 226.60 \\
$\mathbf{1 1}$ & $\mathrm{R} 1=\mathrm{R} 3=\mathrm{H}, \mathrm{R} 2=\mathrm{OH} ; 5^{\prime}$-deoxythymidine (5'-dT) & 225.60 \\
$\mathbf{1 2}$ & $\mathrm{R} 2=\mathrm{R} 3=\mathrm{H}, \mathrm{R} 1=\mathrm{OH}$ 3'-deoxythymidine (3'-dT) & 228.60 \\
\hline
\end{tabular}

Chart

tosine pair is characterized by a well-defined structure, which is independent from the counter ion present during the phase change from solution to the solid state [33]. Remarkably, the crystallization procedures have shown that at weak acid $\mathrm{pH}$, proton-bound homodimers of methylcytosine are preferentially formed even in the presence of a coordinating species such as $\mathrm{AuCl}_{3}$. The structural feature of the proton bound dimer is very similar to the Watson-Crick G.C neutral pair and is characterized by the formation of three hydrogen bonds ranging from 2.812 to $2.916 \AA$.

When the crystallization is performed from calcium

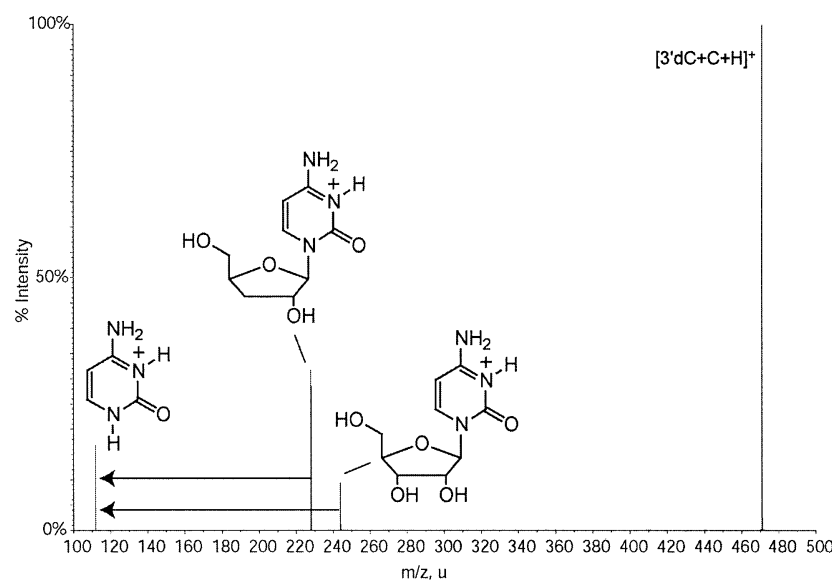

Figure 2. $\mathrm{ESI}(+) \mathrm{CID}$ spectrum of the cluster $\left[\mathrm{C}+3^{\prime}-\mathrm{dC}+\right.$ $\mathrm{H}]^{+}$. perchlorate, the pyrimidine rings are equivalent and the position of the added proton cannot be assigned specifically to one of the two interacting rings, thus showing that a proton is symmetrically shared among two identical nucleobases.

When ESI is used for producing ions directly from their solutions, the phase transition should maintain a memory of the multiple interactions taking place in the condensed phase [34].

It was, therefore, decided to study the unimolecular dissociations of proton bound cytosine nucleoside pairs, aiming at evaluating the existence in the gas phase of triply bonded species. The method of choice was the evaluation of the proton affinity (PA) of cytidine (4), and 2'-deoxycytidine (5) using the appropriate set of cytosine nucleosides (4-8) as reference compounds. The unknown PA of 6 was determined by the simplified approach [22], using adenosine and 2'-deoxyadenosine as reference compounds [35]. The basis of the theory considers that the dissociation of proton bound dimers into the corresponding protonated monomers should occur with negligible entropic effect.

$$
\mathrm{BH}^{+}+\mathrm{B}^{\prime} \leftarrow \mathrm{B}-\mathrm{H}^{+}-\mathrm{B}^{\prime} \rightarrow \mathrm{B}^{\prime} \mathrm{H}^{+}+\mathrm{B}
$$

In a typical experiment, a solution of cytidine (4 or 5$)$ and one of the reference cytidine homologue (4-8) are sprayed from their solutions into a Q $q \mathrm{TOF}$ mass spectrometer. The clusters $\left[\mathrm{B}-\mathrm{H}^{+}-\mathrm{B}^{\prime}\right]$, selected with the first quadrupole $\mathrm{Q}$, are transferred to the reacting region $q$ where they are allowed to dissociate unimolecularly. The products are separated, at high resolving power, by the orthogonal TOF. The two protonated bases $\left(\mathrm{BH}^{+}\right.$and $\left.\mathrm{B}^{\prime} \mathrm{H}^{+}\right)$thus formed may undergo, at a given translational energy, consecutive fragmentations according to their internal energy. The latter can be enhanced by collision with an inert gas kept at constant density. The spectrum reported in Figure 2 displayed, among others, the protonated cytosine at $\mathrm{m} / \mathrm{z} 111$ which may be formed by fragmentation of either two of the primary product ions obtained by the unimolecular competing dissociations of the cluster $\left[\mathrm{C}+3^{\prime}-\mathrm{dC}+\mathrm{H}\right]^{+}$.

The evaluation of the PA of $C(4)$ and $2^{\prime}-\mathrm{dC}(5)$ was therefore carried out by fixing the translational energy of the ions below the experimentally determined threshold of $10 \mathrm{eV}$, which represents the limit for observing the consecutive fragmentation processes displayed by the MS/MS spectrum.

The competitive fragmentation kinetics of $\mathrm{C}$ and $2^{\prime}-\mathrm{dC}$ containing clusters (Table $3 \mathrm{a}, \mathrm{b}$ ) show that the product yields did not correlate with the proton affinities of the interacting nucleosides. The yields of $[\mathrm{C}+$ $\mathrm{H}]^{+}$cations from the dissociation of $\left[\mathrm{C}+2^{\prime}-\mathrm{dC}+\mathrm{H}\right]^{+}$ and $\left[\mathrm{C}+3^{\prime}-\mathrm{dC}+\mathrm{H}\right]^{+}$clusters are 5.73 and $20.90 \%$, respectively, whereas the $\triangle \mathrm{PA}$ between $2^{\prime}-\mathrm{dC}$ and $3^{\prime}-\mathrm{dC}$ is only $0.06 \mathrm{Kcal} / \mathrm{mol}$. Moreover, in the competing dissociations of the heterodimers $\left[\mathrm{C}+\left(2^{\prime}, 5^{\prime}-\mathrm{ddC}\right)+\right.$ $\mathrm{H}]^{+}$the species $\left[2^{\prime}, 5^{\prime}-\mathrm{ddC}+\mathrm{H}\right]^{+}$is largely predomi- 
Table 3. (a) Relative percentage of the product ions produced by the unimolecular dissociations of the protonated homodimers formed by $\mathrm{C}$ and the homologous nucleosides

\begin{tabular}{|c|c|c|c|c|c|}
\hline C & $2^{\prime}-\mathrm{dC}$ & $3^{\prime}-d C$ & $2^{\prime}, 3^{\prime}-\mathrm{ddC}$ & $2^{\prime}, 5^{\prime}-\mathrm{ddC}$ & Clusters ( $\triangle \mathrm{PA}, \mathrm{Kcal} / \mathrm{mol})$ \\
\hline 5.73 & 94.27 & & & & $C / 2^{\prime}-d C(-1.40)$ \\
\hline 20.90 & & 79.10 & & & $C / 3^{\prime}-d C(-1.46)$ \\
\hline 2.29 & & & 97.71 & & $C / 2^{\prime}, 3^{\prime}-d d C(-2.80)$ \\
\hline 18.81 & & & & 81.19 & $C / 2^{\prime}, 5^{\prime}-d d C(+0.20)$ \\
\hline
\end{tabular}

(b) Relative percentage of the product ions produced by the unimolecular dissociations of the protonated homodimers formed by 2'$\mathrm{dC}$ and the homologous nucleosides

\begin{tabular}{|c|c|c|c|c|}
\hline $2^{\prime}-\mathrm{dC}$ & C & $2^{\prime}, 3^{\prime}-\mathrm{dd} C$ & $2^{\prime}, 5^{\prime}-d d C$ & Clusters $(\Delta \mathrm{PA}, \mathrm{Kcal} / \mathrm{mol})$ \\
\hline 94.28 & 5.72 & & & $2^{\prime}-\mathrm{dC} / \mathrm{C}(1.40)$ \\
\hline 29.37 & & 70.63 & & $2^{\prime}-\mathrm{dC} / 2^{\prime}, 3^{\prime}-\mathrm{dC}(-1.40)$ \\
\hline 75.18 & & & 24.82 & $2^{\prime}-d C / 2^{\prime}, 5^{\prime}-d d C(1.60)$ \\
\hline
\end{tabular}

The difference in proton affinity $(\triangle \mathrm{PA})$ between the examined interacting pairs is calculated from the known Pas [24]. the unknown value of $3^{\prime}$-dC was determined as described [22].

nant $(81.19 \%)$ while its PA is $0.2 \mathrm{kcal} / \mathrm{mol}$ lower than that of Cytidine.

This effect is best viewed if a correlation between the intensity ratios $\left(\mathrm{k}_{\mathrm{N}} / \mathrm{k}_{\mathrm{ref}}\right)$ of the dissociations products of each dimer versus the difference between the known $\mathrm{PA}$ of the reference species $\left(\mathrm{PA}_{\text {ref }}\right)$ and its average value $\left(\mathrm{PA}_{\mathrm{avg}}\right)$ is attempted (Figure $\left.3 \mathrm{a}, \mathrm{b}\right)$. This plot provides an estimate of the entropic effect which may affect the determination of an unknown PA by the revised kinetic method [36]. In the experiment here discussed it should give a perfect correlation if the interacting nucleosides form a loosely bound heterodimer, whose dissociation could originate by a single bond cleavage.

The best line fitting the points was, as expected, a logarithmic curve characterized by a correlation coefficient $\left(R^{2}\right)$ of 0.6862 and 0.7398 for $C$ and $2^{\prime}-d C$, respectively.

Further evaluation of the data was carried out for nucleoside $\mathrm{C}$ because of the availability of more reference compounds. The $\mathrm{R}^{2}$ values of 0.8016 and 0.8501 , obtained by excluding two distinct plotting [C $+3^{\prime}-\mathrm{dC}$ $+\mathrm{H}]^{+}$and $\left[\mathrm{C}+2^{\prime}, 5^{\prime}-\mathrm{ddC}+\mathrm{H}\right]^{+}$, respectively, are indicative of a peculiar interaction between the cytosine nucleobases, which was not encountered with other nucleosides [24].

Certainly the worst correlation $\left(R^{2}=0.3692\right)$ was obtained when $2^{\prime}, 3^{\prime}$-ddC was not considered in the plotting, whereas both $\mathrm{C} / 3^{\prime}-\mathrm{dC}$ and $\mathrm{C} / 2^{\prime}, 5^{\prime}$-ddC were used. Furthermore, the lack of correlation is also evident from the plotting of the $\mathrm{PA}_{\text {ref }}$ versus $\mathrm{k}_{\mathrm{N}} / \mathrm{k}_{\text {ref }}$ data in an attempt to determine the PA of the unknown nucleoside (C) by means of the kinetic method, using Nucleosides 5-8 (chart) as reference compounds (Figure 4).

The $\mathrm{PA}_{\mathrm{C}}$ obtained from the intercept was $234.22 \pm$ $1.19 \mathrm{kcal} / \mathrm{mol}$ with an uncertainty inconsistent with the capability of the kinetic method. The situation was even worse when the $\mathrm{PA}_{C}$ was evaluated by matching the unimolecular dissociations of two pairs of heterodimers at a time (Table 4) and averaging the results thus obtained. The average value of $237.09 \mathrm{kcal} / \mathrm{mol}$ is very far from the real value, with a standard deviation of 8.01 $\mathrm{kcal} / \mathrm{mol}$.

The results discussed above show that the kinetics of the competitive dissociation of protonated het-
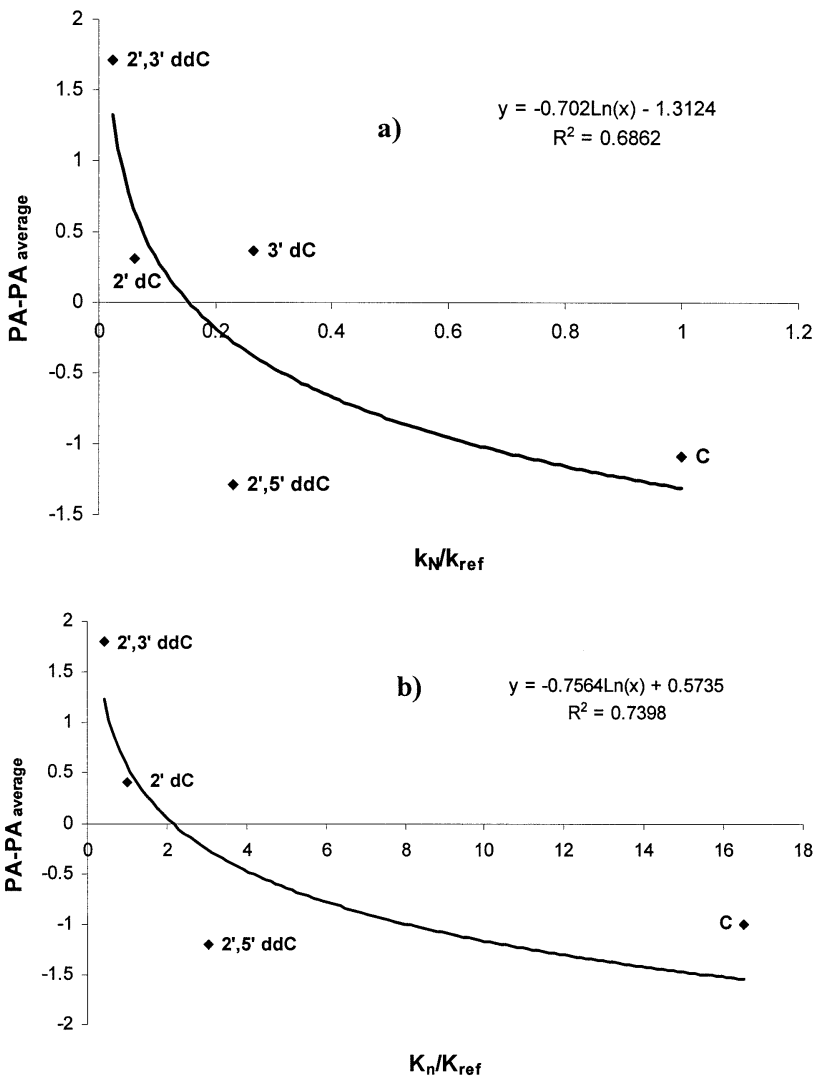

Figure 3. (a) The $\mathrm{PA}_{\text {ref }}-\mathrm{PA}_{\text {avg }}$ values are available in the literature [24] except for $3^{\prime}-\mathrm{dC}$, whose PA was determined by known methods [22]. The product ion $\left(\mathrm{K}_{\mathrm{N}} / \mathrm{K}_{\mathrm{ref}}\right)$ ratio was obtained from the dissociation of the clusters reported in Table 3a (the homodimer of Cytidine [C] was included). (b) The product ion $\left(\mathrm{K}_{\mathrm{N}} / \mathrm{K}_{\mathrm{ref}}\right)$ ratio was obtained from the dissociation of the clusters reported in Table $3 \mathrm{~b}$ (the homodimer of $2^{\prime}$-deoxycytidine $\left(2^{\prime}-\mathrm{dC}\right)$ was included). 


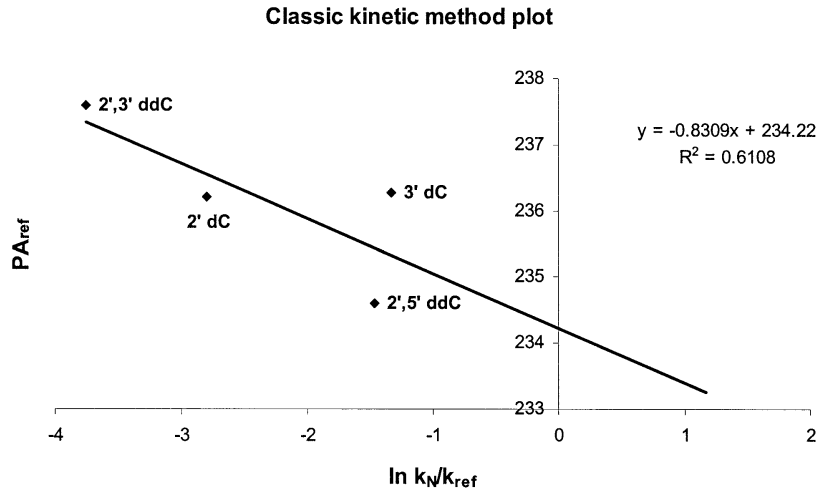

Figure 4. Kinetic method plot for cytidine heterodimers.

erodimers of cytosine nucleosides of type $\left[\mathrm{S}^{1}-\mathrm{Cyt}+\right.$ $\mathrm{S}^{2}$-Cyt $+\mathrm{H}^{+}$into the protonated monomers $\left(\mathrm{S}^{1}-\right.$ $\mathrm{Cyt}+\mathrm{H})^{+}$and $\left(\mathrm{S}^{2}-\mathrm{Cyt}+\mathrm{H}\right)^{+}$, being $\mathrm{S}^{1}$ and $\mathrm{S}^{2}$, the different sugar moieties can not be correlated with the PA of the nucleosides (Table 4). In the case of the heterodimers $\left[\mathrm{C}+3^{\prime}-\mathrm{dC}+\mathrm{H}\right]^{+}$and $\left[\mathrm{C}+2^{\prime}, 5^{\prime}-\mathrm{ddC}+\mathrm{H}\right]^{+}$ the apparent PA of cytosine (C) differs from the real one by nearly $18 \mathrm{Kcal} / \mathrm{mol}$. A general consideration that can be drawn is that substituted cytosine sharing an added proton produces in the gas phase dimers more tightly bound than those obtained when the same nucleosides interact with tertiary alkylamines [22]. Moreover, the structural feature of the sugar units seems to affect to some extent the interaction of the nucleobases.

Theoretical calculations, performed on different $\mathrm{N}-1$ methylcytosine (MeCyt) proton bound dimers, converged to two minimized structures (Table 5) in which cooperative multiple hydrogen bonds exist.

The lowest energy structure (1a, Figure 5) shows the occurrence of three hydrogen bonds between O2, N3 and $\mathrm{N} 4$ of the neutral base and N4, the protonated N3 and $\mathrm{O} 2$, respectively, of the protonated cytosine. The intermolecular distances (N4)-H. ..O2', (N3)-H. . .N3' and $\mathrm{O} 2 . . \mathrm{H}\left(-\mathrm{N} 4^{\prime}\right)$ are $1.768,1.917$ and $2.103 \AA$, respectively. The angles H-N4...O2', H-N3...N3', $\mathrm{H}-\mathrm{N} 4^{\prime} . . \mathrm{O} 2$ are $3.47,1.29$, and $7.16^{\circ}$, respectively.

The protonation of the methylcytosine molecule at N3 produces changes in atomic charges, bond distances, and angles. The largest variations in atomic charges are observed for N3, O2, and C4 (Table 6).

While the protonation causes a more negative charge

Table 4. The apparent PA of cytosine (C) was calculated from each pair of clusters formed by $\mathrm{C}$ and the nucleosides indicated in each line

\begin{tabular}{lc}
\hline CLUSTERS & $\begin{array}{c}\text { PAC } \\
\text { (Kcal/mol). }\end{array}$ \\
\hline \hline $2^{\prime}-d C / 3^{\prime}-d C$ & 236.31 \\
$2^{\prime} d C / 2^{\prime}, 5^{\prime}-d d C$ & 232.85 \\
$2^{\prime}, 3^{\prime}-d d C / 2^{\prime}, 5^{\prime}-d d C$ & 232.69 \\
$2^{\prime}-d C / 2^{\prime}, 3^{\prime} d d C$ & 232.09 \\
$3^{\prime}-d C / 2^{\prime}, 5^{\prime}-d d C$ & 253.07 \\
$3^{\prime}-d C / 2^{\prime}, 3^{\prime}-d d C$ & 235.52 \\
\hline
\end{tabular}

Table 5. Energy values for the structures $1 a, b$ and $2 a, b$

\begin{tabular}{rrcrl}
\hline & HF-6-31G(d) & HF-6-31G(d) ZPVE & SCF +ZPVE & $\Delta E^{\mathrm{c}}$ \\
\hline \hline $1 \mathrm{a}$ & -863.751720 & 0.291416 & -863.460301 & 0 \\
$1 \mathrm{~b}$ & -863.742350 & 0.290305 & -863.452043 & 5.64 \\
$2 \mathrm{a}$ & -1019.896694 & 0.412216 & -1019.484478 & 0 \\
$2 \mathrm{~b}$ & -1019.886039 & 0.411061 & -1019.474978 & 5.96 \\
\hline
\end{tabular}

aUnits of hartree

bZero point vibrational energies corrected by 0.893 ; units of hartree ${ }^{\mathrm{c}} \mathrm{Kcal} / \mathrm{mol}$

for N3 $\left(-0.996\right.$ in $\mathrm{MeCyt}^{+}$versus -0.873 in $\left.\mathrm{MeCyt}\right)$, both $\mathrm{O} 2$ and $\mathrm{C} 4$ became more positive in the methylcytosinum cation. The charge on $\mathrm{H} 3$ is 0.554 . The overall charge is 0.910 for the methylcytosinium cation and 0.090 for the neutral methylcytosine of the dimer.

The bond lengths N3-C4 and N3-C2 show an elongation in $\mathrm{MeCyt}^{+}$in comparison with $\mathrm{MeCyt}$, while the bonds $\mathrm{C} 2-\mathrm{O} 2$ and $\mathrm{C} 4-\mathrm{N} 4$ result to be shortened (Table 7). Variations also occur in bond angles: $\mathrm{C} 2-\mathrm{N} 3-\mathrm{C} 4$ is more open in the methylcytosinium cation $\left(125.2^{\circ}\right)$ than in the neutral molecule $\left(120.7^{\circ}\right)$, while the opposite trend is observed for the $\mathrm{N}(1)-\mathrm{C}(2)-\mathrm{N}(3)$ and $\mathrm{N}(3)-\mathrm{C}(4)-\mathrm{C}(5)$ bond angles. The methylcytosiniummethylcytosine base pair through three hydrogen bonds observed in 1a is in agreement with similar reported structures [37-40].

The other energy minimum structure (1b), having a higher energy content $\left(\Delta \mathrm{E}_{(1 \mathrm{~b}-1 \mathrm{a})}=5.64 \mathrm{kcal} / \mathrm{mol}\right)$, shows a double hydrogen interaction between the $\mathrm{O} 2$ of the neutral molecule and the protonated N3 together with the N4 of the neighbor molecule (Figure 6). This causes the two molecules to be in a syn position. The distances (N3-)H. . .O2' and (N4-)H. . .O2' are 1.887 and $1.946 \AA$, respectively, while (N4-)H weakly interacts with $\mathrm{N}^{\prime}$ ( $\mathrm{d}$ $\left.\left(\mathrm{H} . . \mathrm{N} 3^{\prime}\right)=2.634 \AA\right)$. The angles H-N3...O2' and $\mathrm{H}-\mathrm{N} 4 . . \mathrm{O} 2^{\prime}$ are 21.48 and $23.93^{\circ}$, respectively. In both $\mathbf{1 a}$ and $\mathbf{1 b}$, the methylcytosinium-methylcytosine system is planar. The same geometric variations observed after protonation for $\mathbf{1 a}$ also occur in $\mathbf{1 b}$ (Table 7).

In order to simulate the role exerted by the sugar moiety, the methyl group at $\mathrm{N}(1)$ in $\mathbf{1 a}$ and $\mathbf{1 b}$ was

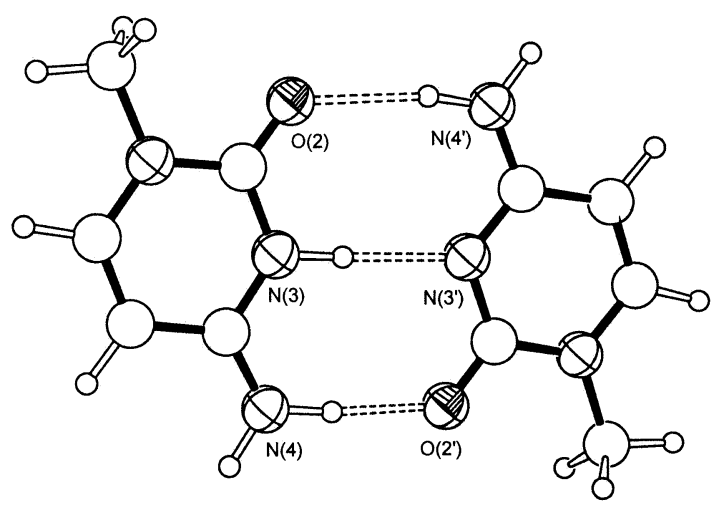

Figure 5. The lowest energy minimized Structure 1a for the N-1-methylcytosine proton bound dimer. 
Table 6. Atomic charges for the methylcytosiniummethylcytosine system $1 \mathrm{a}$

\begin{tabular}{lrrr}
\hline Atom & MeCyt & MeCyt $^{+}$ & $\begin{array}{r}\Delta \text { (MeCyt }^{+} \\
- \text {MeCyt) }\end{array}$ \\
\hline \hline N1 & -0.730 & -0.750 & -0.019 \\
C1 & -0.282 & -0.295 & -0.013 \\
C2 & 1.058 & 1.094 & 0.037 \\
O2 & -0.724 & -0.610 & 0.115 \\
N3 & -0.873 & -0.996 & -0.123 \\
C4 & 0.743 & 0.826 & 0.082 \\
N4 & -0.953 & -0.954 & -0.001 \\
C5 & -0.385 & -0.391 & -0.007 \\
C6 & 0.200 & 0.221 & 0.021 \\
H1A & 0.191 & 0.206 & 0.014 \\
H1B & 0.219 & 0.234 & 0.015 \\
H1C & 0.219 & 0.234 & 0.015 \\
H3 & & 0.554 & 0.554 \\
H4A & 0.477 & 0.544 & 0.066 \\
H4B & 0.413 & 0.431 & 0.018 \\
H5 & 0.249 & 0.288 & 0.039 \\
H6 & 0.268 & 0.274 & 0.006 \\
SUM & 0.090 & 0.910 & \\
\hline
\end{tabular}

replaced by an isopropyl moiety. The resulting structures (IspCyt, $\mathbf{2 a}$ and $\mathbf{2 b}$ ) were fully optimized. In the absolute energy minimum Structure 2a (Figure 7) the increase of the steric hindrance of the substituent at $\mathrm{N}(1)$ maintains three hydrogen bonding interactions between the two units, with distances (N4)-H. . O2', (N3)-H. . .N3' and O2. ..H(-N4') are 1.763, 1.941, and
$2.076 \AA$, respectively. The two six- membered rings lie on the same plane (Figure 7).

The energy minimized Structure (2b , Figure 8 ) obtained by replacing the methyl group in $\mathbf{1 b}$ with an isopropyl shows a increase of energy content of about 6 $\mathrm{kcal} / \mathrm{mol}$ in respect to $2 \mathrm{a}\left(\Delta \mathrm{E}_{(2 \mathrm{~b}-2 \mathrm{a})}=5.96 \mathrm{kcal} / \mathrm{mol}\right)$. In this case, the presence of the relatively large group at $\mathrm{N}(1)$ causes changes in the mutual orientation of the two bases. In fact the dihedral angle between the least squares planes defined by the each base is $8.51^{\circ}$ (Figure 8).

In this structure the strongest intermolecular hydrogen bonding are between (N3)-H...O2' and (N4)-H. . .N3' and (N4)-H. . .O2' with distances equal to $1.819,2.187$, and $2.307 \AA$, respectively.

Crystalline N-1-methylcytosine homodimers provided, by X-rays diffractometry, the structure reported in Figure 9. The triply bonded structure is confirmed with the geometry of the cation quite similar to that of the hemiidroiodide, hemihydrohexafluorosilicate, and hemihydrogoldtetracianide of N-1-methylcytosine [41]. Nevertheless, an important difference has been observed with respect to the previously reported structures. In this compound the two pyrimidyl rings are crystallographically equivalent because of the presence of an inversion center. Consequently, the intermolecular distances $\mathrm{N}(4)$. . .O(2a) [2.816(4) $\AA$ ] are equal. In all the other cases the $\mathrm{H}$ bonds between $\mathrm{N}(4)$ of the protonated base and $\mathrm{O}(2)$ of the neutral one are signif-

Table 7. Geometric parameters for the $\mathbf{1} \mathbf{a}, \mathbf{b}$ and $\mathbf{2} \mathbf{a}, \mathbf{b}$ proton bound dimers

\begin{tabular}{|c|c|c|c|c|c|c|c|c|}
\hline & \multicolumn{2}{|c|}{$1 \mathrm{a}$} & \multicolumn{2}{|c|}{$1 b$} & \multicolumn{2}{|c|}{$2 a$} & \multicolumn{2}{|c|}{$2 b$} \\
\hline & $\mathrm{MeCyt}^{+}$ & MeCyt & $\mathrm{MeCyt}^{+}$ & MeCyt & IspCyt $^{+}$ & IspCyt & IspCyt ${ }^{+}$ & IspCyt \\
\hline$N(1)-C(2)$ & 1.375 & 1.381 & 1.382 & 1.380 & 1.376 & 1.384 & 1.384 & 1.384 \\
\hline$C(2)-N(3)$ & 1.378 & 1.350 & 1.385 & 1.342 & 1.381 & 1.351 & 1.387 & 1.351 \\
\hline$N(3)-C(4)$ & 1.344 & 1.319 & 1.342 & 1.312 & 1.343 & 1.318 & 1.337 & 1.312 \\
\hline $\mathrm{N}(3)-\mathrm{H}$ & 1.024 & & 1.009 & & 1.023 & & 1.012 & \\
\hline$C(4)-C(5)$ & 1.427 & 1.433 & 1.424 & 1.433 & 1.425 & 1.431 & 1.421 & 1.429 \\
\hline$C(5)-C(6)$ & 1.344 & 1.340 & 1.347 & 1.340 & 1.344 & 1.340 & 1.348 & 1.341 \\
\hline$C(6)-N(1)$ & 1.354 & 1.354 & 1.350 & 1.355 & 1.355 & 1.356 & 1.350 & 1.355 \\
\hline $\mathrm{C}(2)-\mathrm{O}(2)$ & 1.194 & 1.218 & 1.189 & 1.224 & 1.195 & 1.220 & 1.186 & 1.219 \\
\hline$C(4)-N(4)$ & 1.301 & 1.326 & 1.305 & 1.332 & 1.301 & 1.326 & 1.309 & 1.333 \\
\hline$N(1)-C(1)$ & 1.470 & 1.464 & 1.470 & 1.463 & 1.497 & 1.492 & 1.501 & 1.492 \\
\hline$N(1)-C(2)-N(3)$ & 115.7 & 119.3 & 114.9 & 119.9 & 115.7 & 119.4 & 115.0 & 119.7 \\
\hline$C(2)-N(3)-C(4)$ & 125.2 & 120.7 & 125.7 & 120.1 & 125.5 & 121.0 & 126.0 & 120.6 \\
\hline$N(3)-C(4)-C(5)$ & 117.4 & 121.6 & 117.4 & 122.3 & 117.2 & 121.3 & 117.3 & 121.9 \\
\hline$C(4)-C(5)-C(6)$ & 117.6 & 116.4 & 117.4 & 116.0 & 117.3 & 116.2 & 117.2 & 116.0 \\
\hline$C(5)-C(6)-N(1)$ & 123.4 & 122.0 & 123.7 & 121.8 & 124.0 & 122.9 & 124.5 & 122.8 \\
\hline$C(1)-N(1)-C(2)$ & 117.1 & 118.1 & 116.6 & 118.4 & 119.0 & 121.5 & 120.0 & 119.1 \\
\hline $\mathrm{O}(2)-\mathrm{C}(2)-\mathrm{N}(3)$ & 121.7 & 122.3 & 121.9 & 121.7 & 120.6 & 121.2 & 120.7 & 120.7 \\
\hline$N(3)-C(4)-N(4)$ & 119.1 & 118.4 & 118.9 & 117.9 & 119.2 & 118.5 & 119.4 & 118.3 \\
\hline $\mathrm{O}(2) \ldots \mathrm{H}\left(\mathrm{N}\left(4^{\prime}\right)\right)$ & 2.101 & & & & 2.076 & & & \\
\hline$(\mathrm{N} 3)-\mathrm{H} . \ldots \mathrm{N}\left(3^{\prime}\right)$ & 1.924 & & & & 1.941 & & & \\
\hline (N4)-H. . O (2') & 1.769 & & 1.951 & & 1.763 & & 2.307 & \\
\hline (N3)-H. . .O(2') & & & 1.894 & & & & 1.819 & \\
\hline $\mathrm{O}(2) \ldots \mathrm{H}-\mathrm{N}\left(4^{\prime}\right)$ & 169.3 & & & & 170.2 & & & \\
\hline $\mathrm{N}(3)-\mathrm{H} . \ldots \mathrm{N}\left(3^{\prime}\right)$ & 177.9 & & & & 178.7 & & & \\
\hline $\mathrm{N}(4)-\mathrm{H} . \ldots \mathrm{O}\left(2^{\prime}\right)$ & 174.5 & & 143.9 & & 175.4 & & 134.2 & \\
\hline $\mathrm{N}(3)-\mathrm{H} . \ldots \mathrm{O}\left(2^{\prime}\right)$ & & & 147.1 & & & & 158.1 & \\
\hline
\end{tabular}




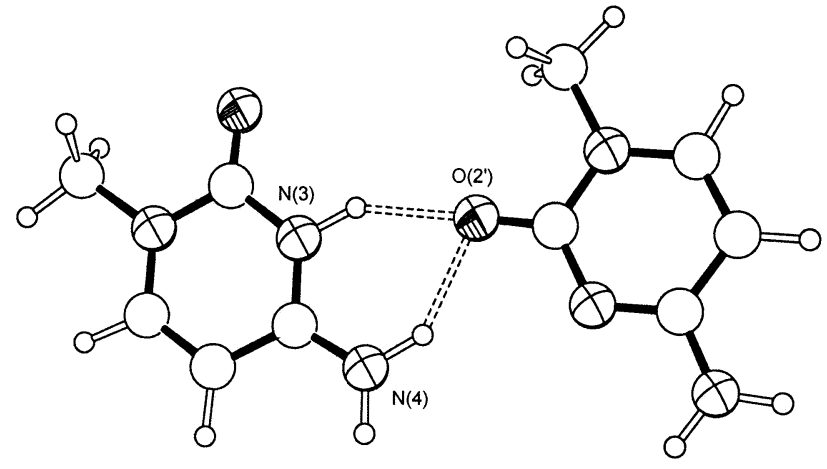

Figure 6. Local energy minimum $\mathbf{1 b}$ for the N-1-methylcytosine proton bound dimer.

icantly shorter than those between $\mathrm{N}(4)$ of the neutral base and $\mathrm{O}(2)$ of the protonated one. Consequently, it seems reasonable to suppose that, in our case, hydrogen atom on $\mathrm{N}(3)$ is equally shared between the two rings. The intermolecular distance (N3). . .N(3a) is 2.818(4) $\AA$, slightly shorter than in similar structures previously reported.

Very recently, we demonstrated that nucleosides can be used as reference compounds in the evaluation by the kinetic method of the unknown PA of other nucleosides, especially in the case of thymidine [24].

No solid-phase structures regarding the interaction of protonated pairs of substituted thymines has been reported in the Cambridge crystallographic database. We are also unaware of any reported identification of multiply- or singly-bonded thymine derivative in the solution phase. We have therefore applied the same mass spectrometric method to the detection of thyminenucleoside heterodimers in the gas phase. Accordingly, the energetics of the gas phase dissociations of heterodimers formed between 5-methyl Uridine (9, 5-MeU)
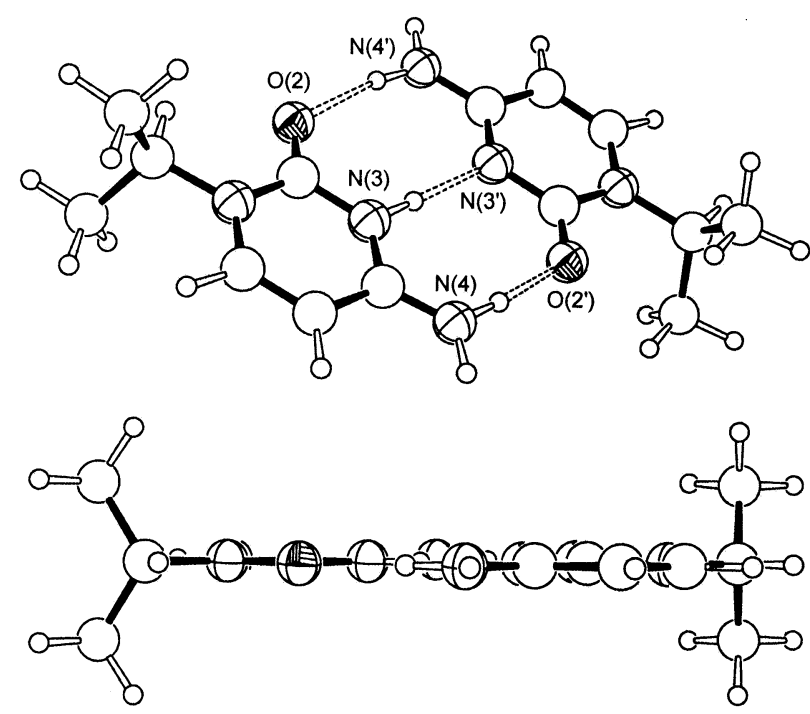

Figure 7. Two views of the energy minimum Structure $G$ for the N-1-isopropyl-cytosinium-cytosine proton bound dimer.
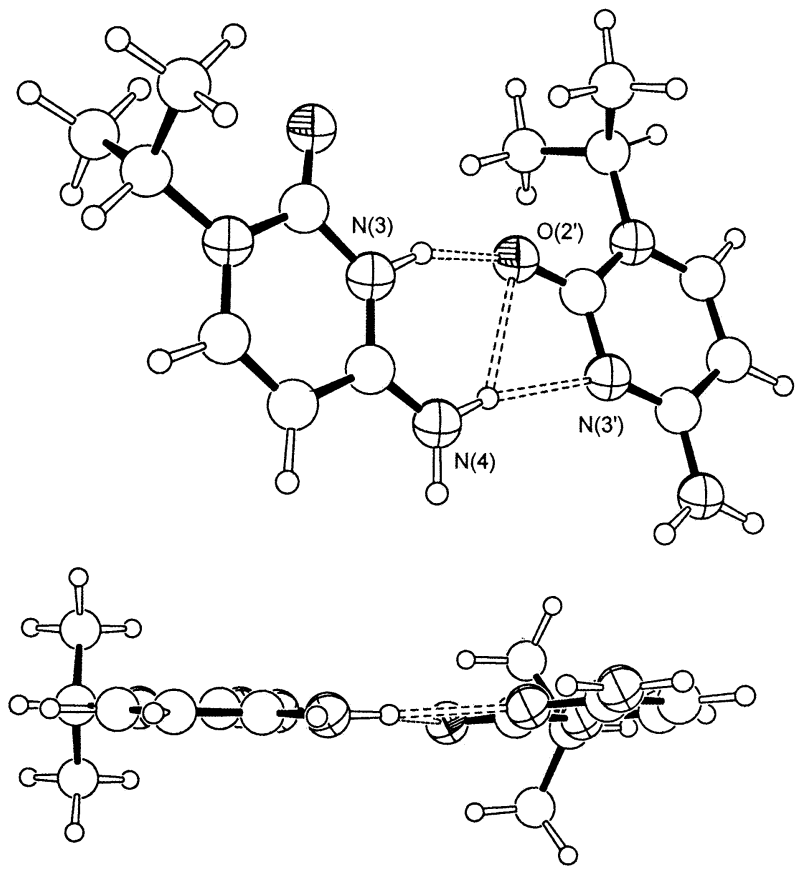

Figure 8. Two views of the local energy minimum Structure $\mathbf{2 b}$ for the N-1-isopropyl cytosine proton bound dimer.

and the homologous nucleosides 10-12 (chart) was evaluated. By analogy with the experiments with cytosine nucleosides, the PA of 9 was re-evaluated using the known PAs of 10-12. Figure 10 shows the ESI-MS/MS spectrum of the dimer $[\mathrm{T}+\mathrm{H}+5 \mathrm{MeU}]^{+}$taken at an accelerating voltage of $10 \mathrm{eV}$, which can be considered typical of protonated thymine nucleoside heterodimers. Unlike the MS/MS spectra of cytidine analogs, no consecutive fragment ions due to the loss of the sugar moiety are, in fact, shown. It was, therefore, possible to

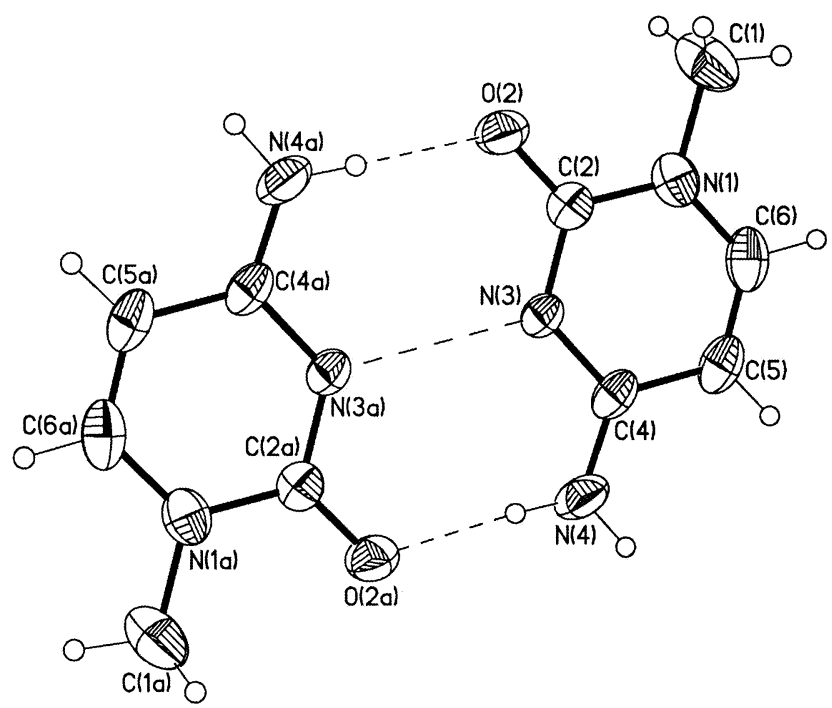

Figure 9. View of $[(1-\mathrm{MeCytH}) \cdot(1-\mathrm{MeCyt})](\mathrm{ClO} 4)$ (1). (Symmetry operation $\mathrm{a}:-\mathrm{x},-\mathrm{y}+1,-\mathrm{z}+1)$. 


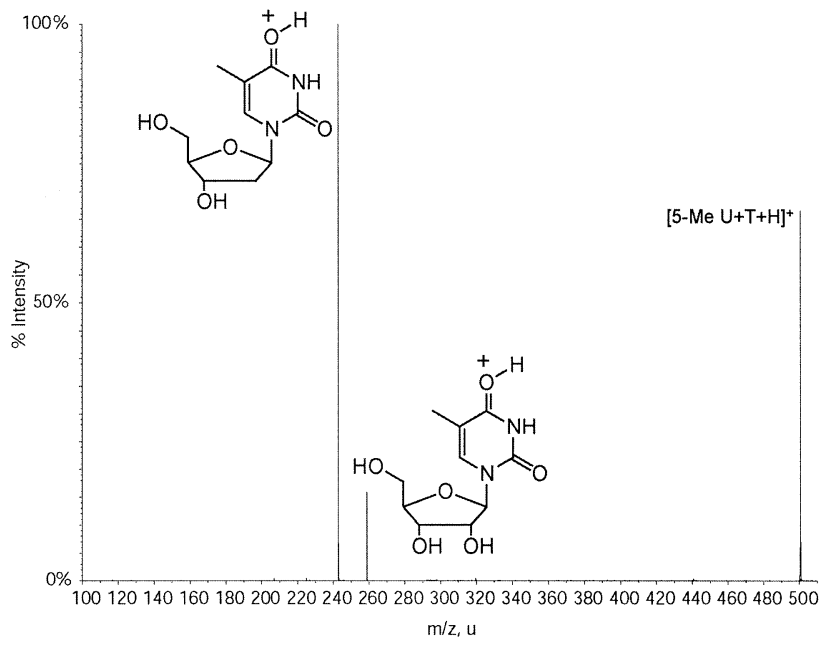

Figure 10. ESI $(+)$ CID spectrum of the cluster $[\mathrm{T}+$ $5-\mathrm{MeU}+\mathrm{H}]^{+}$.

treat the data with the extended kinetic method and its derived formulations.

Table 8 shows the intensities of the monomers generated in a MS/MS experiment at different collision energies (i.e., $\mathrm{eV} \mathrm{4}, \mathrm{eV} \mathrm{6,} \mathrm{eV} \mathrm{8,} \mathrm{and} \mathrm{eV} 10$ ).

The logarithm curves obtained at different collision energy by plotting PA-PA $A_{\text {avg }}$ versus the intensity ratios of the protonated T-nucleoside fragments $\left(\mathrm{k}_{\mathrm{N}} / \mathrm{k}_{\mathrm{ref}}\right)$, formed by the dissociation of the examined gaseous clusters, provided good correlation factors, all very closed to the $R^{2}$ value of 0.9297 obtained at $10 \mathrm{eV}$ (Figure 11). Some consideration can be drawn from this preliminary observation. The similarity of the four regression curves, and of course, of the $\mathrm{k}_{\mathrm{N}} / \mathrm{k}_{\text {ref }}$ ratios, indicate that the threshold for the unimolecular dissociation of the various heterodimers can be put at very low collision energy, probably lower than $4 \mathrm{eV}$. Accordingly, in the case of T-nucleosides, loosely bound clus-

Table 8. Experimental data for the determination of the proton affinity by ESI-MS/MS of nucleosides 9

\begin{tabular}{|c|c|c|c|c|}
\hline & Cluster & \multicolumn{3}{|c|}{ 5-MeU/T 5-MeU/5'-dT 5-MeU/3'-dT } \\
\hline & PA [24] (kcal/mole) & 226.60 & 225.60 & 228.20 \\
\hline \multirow[t]{4}{*}{ eV 4} & 5-MeU & 13.73 & 57.98 & 4.44 \\
\hline & $\mathrm{T}$ & 86.27 & & \\
\hline & $5^{\prime}-d T$ & & 42.02 & \\
\hline & $3^{\prime}-\mathrm{dT}$ & & & 95.56 \\
\hline \multirow[t]{4}{*}{ eV 6} & 5-MeU & 13.44 & 57.95 & 4.03 \\
\hline & $\mathrm{T}$ & 86.56 & & \\
\hline & $5^{\prime}-\mathrm{dT}$ & & 42.05 & \\
\hline & $3^{\prime}-d T$ & & & 95.97 \\
\hline \multirow[t]{4}{*}{ eV 8} & 5-MeU & 13.83 & 57.87 & 3.99 \\
\hline & $\mathrm{T}$ & 86.17 & & \\
\hline & $5^{\prime}-\mathrm{dT}$ & & 42.13 & \\
\hline & $3^{\prime}-\mathrm{dT}$ & & & 96.01 \\
\hline \multirow[t]{4}{*}{ eV 10} & 5-MeU & 13.79 & 57.87 & 3.77 \\
\hline & $\mathrm{T}$ & 86.21 & & \\
\hline & $5^{\prime}-\mathrm{dT}$ & & 42.13 & \\
\hline & $3^{\prime}-\mathrm{dT}$ & & & 96.23 \\
\hline
\end{tabular}

Regression curve eV 10

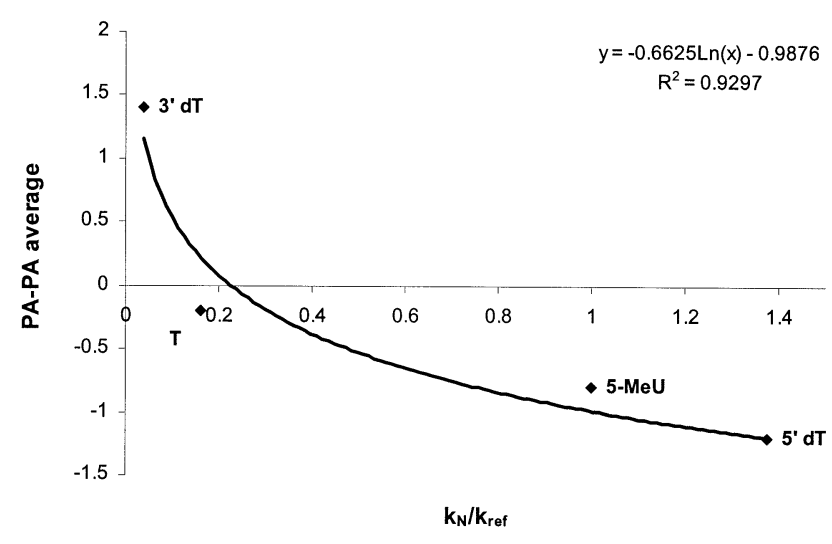

Figure 11. Logarithm curves obtained at $10 \mathrm{eV}$ collision energy by plotting PA-PA $\mathrm{avg}_{\text {v }}$ versus the intensity ratios of the protonated T-nucleoside fragments.

ters are formed. Moreover, the excess energy above the threshold for the dissociations is not enough to cause the formation of vibrationally excited protonated monomers which might further dissociate. It should be expected, therefore, that the interaction between protonbound T-nucleosides should be energetically similar to the cluster formed by a single T-nucleoside and tertiary alkylamines [22].

A direct proof is offered by the re-evaluation of the PA of 5-MeU from the new data, according to Armentrout's approach [36] (Figures 12 and 13), and matching the value thus obtained with that determined with the simplified version of the kinetic method [22].

By this approach, however, if the experiments are carried out at different $\mathrm{T}_{\text {eff }}$ (hence at different internal

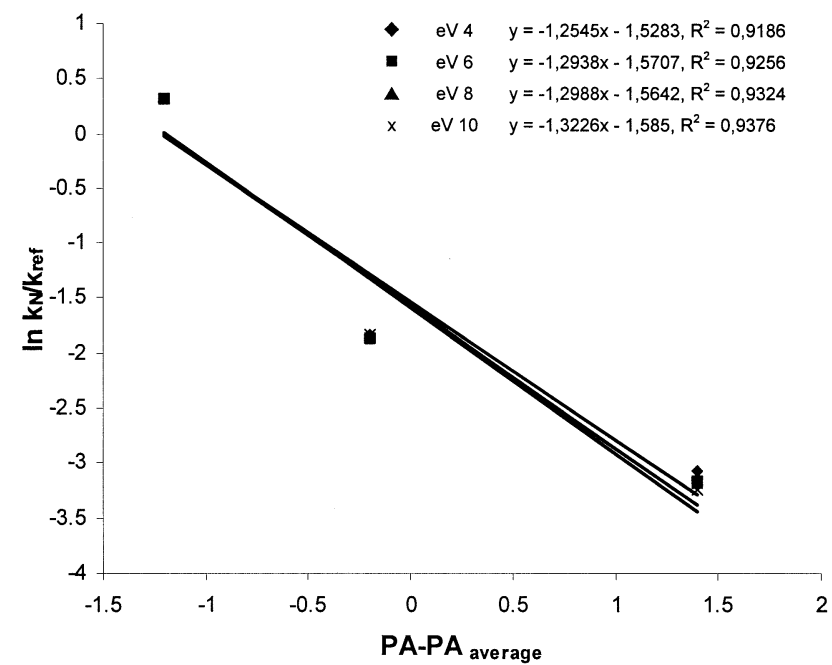

Figure 12. Evaluation of $-1 / \mathrm{RT}_{\text {eff }}$ (from the slope) and $\left(\mathrm{GB}_{\mathrm{app}}{ }^{-}\right.$ $\mathrm{PA}_{\mathrm{avg}}$ ) $/ 1 / \mathrm{RT}_{\text {eff }}$ (from the intercept) parameters at four different collision energies $(\mathrm{eV} 4, \mathrm{eV} 6, \mathrm{eV} 8, \mathrm{eV} 10)$ in the collision cell $\mathrm{q}$ of a QqTOF instrument. The $\ln \left(\mathrm{k}_{\mathrm{N}} / \mathrm{k}_{\mathrm{ref}}\right)$ values were obtained, for each experimental condition, from the proton-bound dimers generated by ESI from nucleoside $\mathbf{9}$ and the reference nucleosides 10-12. 


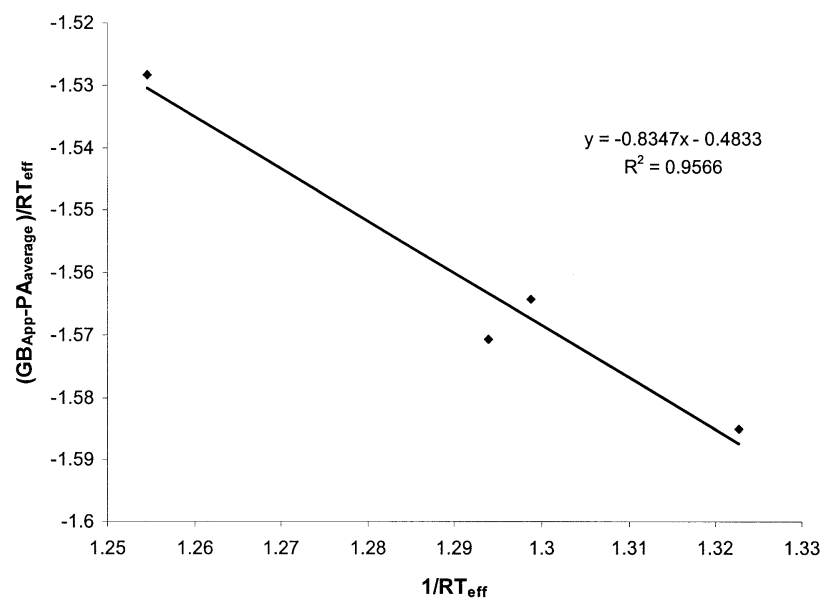

Figure 13. Evaluation of the thermodynamic quantities of 9 from the parameters obtained from the linear regression of figure 12 . $\mathrm{PA}=225.97 \pm 0.13 \mathrm{kcal} / \mathrm{mol}, \Delta \Delta \mathrm{S}=-0.962 \mathrm{cal} / \mathrm{mol} \mathrm{K}$.

energies for the dimer), the evaluation of the entropic term could be achieved. It is possible to evaluate the entropic term by performing a number of MS/MS experiments at different collision energies. In particular, in the case of an instrument having the ESI QqTOF configuration, the energy may be varied in two main different ways: (1) By changing the collision gas pressure in the collision cell $q$; the higher the pressure, the stronger are the collisions between the gas and the sample. Specifically, in commercial instruments there are six levels of collision gas pressure (CAD 1, CAD 2, CAD 3, CAD 4, CAD 5, CAD 6); (2) by changing the potential at the entrance of the collision gas cell leaving unchanged the collision gas pressure. In this situation, ions are accelerated into the collision cell depending on the potential applied. The instrumental parameter change is called the $\mathrm{eV}$ potential and may vary between 1 and $50 \mathrm{~V}$. The method requires plotting, at a given collision energy, the logarithm of the ratio intensities given by the product ions of each fragmenting dimer versus the PA of each reference compound minus the PA averaged over all references. The resulting plot

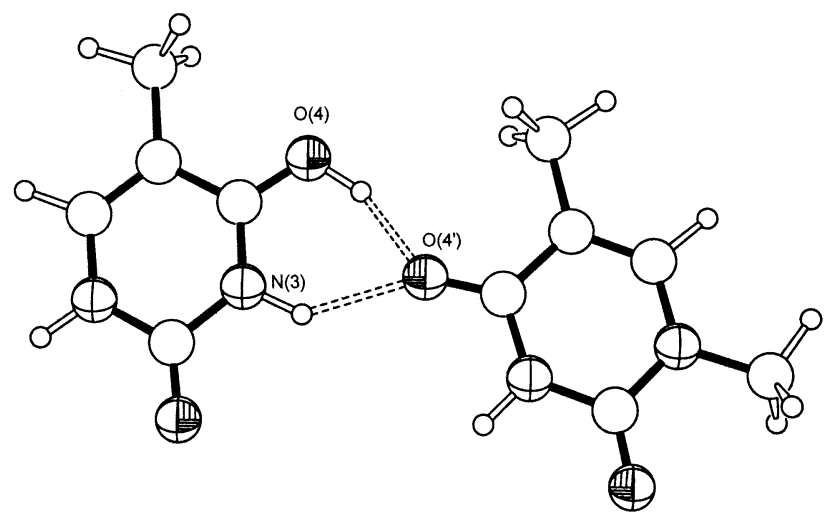

Figure 14. Energy minimum structure for the (O4-H)-thyminium-N(1)-methylthymine proton bound dimer 3 .
Table 9. Geometric parameters for the $\mathrm{Thy}^{+}-$MeThy proton bound dimer 3

\begin{tabular}{lcc}
\hline & Thy $^{+}$ & MeThy \\
\hline \hline $\mathrm{N}(1)-\mathrm{C}(2)$ & 1.372 & 1.373 \\
$\mathrm{C}(2)-\mathrm{N}(3)$ & 1.393 & 1.385 \\
$\mathrm{C}(2)-\mathrm{O}(2)$ & 1.181 & 1.188 \\
$\mathrm{C}(4)-\mathrm{C}(5)$ & 1.423 & 1.443 \\
$\mathrm{C}(4)-\mathrm{O}(4)$ & 1.276 & 1.229 \\
$\mathrm{O}(4)-\mathrm{H}(4)$ & 0.979 & \\
$\mathrm{O}(4)-\mathrm{N}(3)$ & 1.322 & 1.356 \\
$\mathrm{C}(5)-\mathrm{C}(6)$ & 1.350 & 1.343 \\
$\mathrm{C}(6)-\mathrm{N}(1)$ & 1.355 & 1.362 \\
$\mathrm{C}(5)-\mathrm{Me}$ & 1.509 & 1.506 \\
$\mathrm{C}(5)-\mathrm{Me}$ & 1.509 & 1.506 \\
$\mathrm{~N}(1)-\mathrm{Me}$ & & 1.467 \\
$\mathrm{~N}(1)-\mathrm{C}(2)-\mathrm{N}(3)$ & 112.5 & 114.1 \\
$\mathrm{C}(2)-\mathrm{N}(3)-\mathrm{C}(4)$ & 125.3 & 127.3 \\
$\mathrm{~N}(3)-\mathrm{C}(4)-\mathrm{C}(5)$ & 120.4 & 116.1 \\
$\mathrm{C}(4)-\mathrm{C}(5)-\mathrm{C}(6)$ & 114.9 & 116.7 \\
$\mathrm{C}(5)-\mathrm{C}(6)-\mathrm{N}(1)$ & 123.2 & 124.8 \\
$\mathrm{C}(6)-\mathrm{N}(1)-\mathrm{C}(2)$ & 123.8 & 121.0 \\
$\mathrm{O}(2)-\mathrm{C}(2)-\mathrm{N}(3)$ & 122.5 & 121.9 \\
$\mathrm{Me}-\mathrm{N}(1)-\mathrm{C}(2)$ & & 116.8 \\
$\mathrm{Me}-\mathrm{C}(5)-\mathrm{C}(4)$ & 120.6 & 119.7 \\
$(\mathrm{O} 2)-\mathrm{H} . . \mathrm{O}\left(4^{\prime}\right)$ & 1.680 & \\
$(\mathrm{~N} 3)-\mathrm{H} . . \mathrm{O}\left(4^{\prime}\right)$ & 1.986 & \\
$\mathrm{O}(2)-\mathrm{H} . . \mathrm{O}\left(4^{\prime}\right)$ & 159.2 & \\
$\mathrm{~N}(3)-\mathrm{H} . . \mathrm{O}\left(4^{\prime}\right)$ & 137.7 & \\
\hline & & \\
\hline & &
\end{tabular}

gives a series of straight lines (Figure 12) whose slopes represent the $-1 / \mathrm{RT}$ values while the intercepts represents the $\left(\mathrm{GB}_{\text {app }}-\mathrm{PA}_{\text {average }}\right) / \mathrm{RT}$ value according to the Armentrout method.

Figure 13 describes a plot of the negative of the slopes versus the intercepts obtained in the first graph. The PA of 5-MeU may be easily calculated by the slope $\left(m_{2}\right)$ of the line obtained in Figure 13 according to eq 2 [36]. A statistical treatment of the plot allows estimating even the errors of the extrapolated values.

$$
\begin{aligned}
m_{2} & =\mathrm{PA}_{5 \mathrm{MeU}}-\mathrm{PA}_{\text {average }} \Rightarrow \mathrm{PA}_{5 \mathrm{MeU}} \\
& =225.97 \pm 0.13(\mathrm{kcal} / \text { mole })
\end{aligned}
$$

Whereas the entropy variation, obtained from the graph in Figure 13 is: $\Delta \Delta S=-0.962 \mathrm{cal} / \mathrm{mol} \mathrm{K}$.

The first consideration to be drawn is that the $\mathrm{PA}_{5-\mathrm{MeU}}$ thus obtained is practically identical to the value already known [22]. This is a consequence of the structure of the protonated heterordimers interacting through thymine nucleobases. An important clue on the formation of a loosely bound complex is given by the value of the activation entropy experimentally determined. The hypothesis that thymine nucleosides do not form multiply bound complexes [24] is confirmed by the data discussed above. The lack of data on the solid phase structure of protonated thymine complexes are probably due to the softness of the interaction between the two nucleobases which prevents the formation of stable clusters which might provide crystalline structures. 
In the case of the clustering of Cytosine nucleosides both experimental data, in the solid and in the gas phase, and theoretical calculations, led to the same conclusion, i.e., the existence of multiply bound cytidine protonated dimers.

$N$-1-methylthymine (MeThy) was chosen as a nucleoside model for obtaining information on the gas phase structure of protonated dimers, whose existence was demonstrated by mass spectrometry.

The energy minimized structure of the $(\mathrm{O} 4-\mathrm{H})$-thyminium-N(1)-methylthymine proton bound dimer (3, Figure 14) shows that the interactions involve the two $\mathrm{O} 4$ oxygens of the nucleobases and N3 of the protonated moiety (Table 9) with the two bases coplanar. The atomic charge on $\mathrm{O}(4)$ is -0.78 in MeThy and -0.70 in Thy + . As expected, the largest variation in bond lengths is the elongation of the $\mathrm{C}(4)-\mathrm{O}(4)$ distance that has values of 1.229 in MeThy and $1.276 \AA$ in $\mathrm{Thy}^{+}$. The opposite trend is observed for $\mathrm{N}(3)-\mathrm{C}(4)$ and $\mathrm{C}(4)-\mathrm{C}(5)$ for which a shortening of about $0.02 \AA$ is observed in $\mathrm{Thy}^{+}$in respect to MeThy. The bond angle $\mathrm{N}(3)-\mathrm{C}(4)-\mathrm{C}(5)$ is wider in $\mathrm{Thy}^{+}\left(120.4^{\circ}\right)$ than in MeThy $\left(116.1^{\circ}\right)$.

\section{Conclusions}

The involvement of protonated nucleosides in the tertiary structure of multiply stranded DNA biopolymers is due, from a chemical point of view, to the attainment, in water, of the proper conformation which drives the formation of interstrand hydrogen bonds of both Watson-Crick and Hoogsteen types. When the exploitation of this type of interaction is carried out on models, usually alkylated nucleobases or nucleosides, the need of polar solvents to dissolve the analytes prevents the formation of intermolecular hydrogen bonding. This drawback has been overcome by applying lipophilic tags on the sugar moiety of the nucleoside and investigating the horizontal interactions of nucleobases in non polar and aprotic solvents [42]. The extrapolation of the results thus obtained to the wild-type molecule requires that solvent and substituent effect can be neglected. On the contrary, evidence has been previously presented (vide infra) that hydrogen bondings between two homologous nucleosides is deeply affected, at least in the case of C-nucleosides, by the substituent present in the sugar moiety. Similarly, the interaction between $N$-1-propylthymine and acylated triazine derivatives is affected by conformational equilibria [43].

A number of ESI experiments [34] support the observation that equilibria occurring in the condensed phase can be "frozen" to some extent during the spray procedure. Hence, the structure of complex species in the gas phase may reflect the molecular arrangements they have already achieved in solutions.

Moreover the formation of ordered crystal structures from solvated nucleoside salts in acid media could reflect a similar principle. An immediate consequence is that the solid phase and the gas phase, under vacuum conditions, could represent the appropriate environment to take a snapshot the dynamics of the equilibria taking place in solution. The advantage of X-ray data, which provide information on the counterions and solvent molecules eventually involved in the structure, is counterbalanced by the properties of an isolated environment, such as the gas phase under high vacuum conditions, where even weakly-bound complexes are detectable.

The family of C-nucleosides (4-8) forms in the solid and in the gas phase an extremely regular arrangement of proton-bound heterodimers stabilized by the presence of three hydrogen bonds between the two nucleobases. The bond parameters are similar to those of the Watson-Crick structure of the neutral $C-G$ dimer. Remarkably, the information obtained from $X$-ray analysis and ESI mass spectrometry are nearly identical and match perfectly the simulation performed in the gas phase by theoretical calculation.

The uniqueness of ESI-MS/MS method is represented by the possibility of studying species as transient as the proton bound thymine nucleoside family (9-12). Thymine is the less basic nucleoside in solution [44] and in the gas phase [22]. The theoretical calculations have shown that a couple of nucleosides interact through a strong $\mathrm{OH}-\mathrm{O}$ hydrogen bond $(\mathrm{d} \mathrm{H}-\mathrm{O}=1.680 \AA)$ and a weaker $\mathrm{NH}-\mathrm{O}$ interaction $(\mathrm{d} \mathrm{H}-\mathrm{O}=1.986 \AA)$; these data are in agreement with the mass spectrometric investigation. The lack of information on the existence of any solid phase structure could reflect the lability of thymine-thymine proton-bound dimers.

\section{References}

1. (a) Saenger, W. Principles of Nucleic Acid Structure; SpringerVerlag: New York, NY, 1984. (b) Eckstein, F.; Lilley, D. M. J. Nucleic Acids and Molecular Biology; Springer-Verlag: Berlin and Heidelberg, 1990, p. 2.

2. Frank-Kamenetskii, M. D.; Mirkin, S. M. Annu. Rev. Biochem. 1995, 64, 65.

3. Soyfer, V. N.; Potaman, V. N. Triple-Helical Nucleic Acid; Springer-Verlag: New York, NY, 1996.

4. Chubb, J. M.; Hogan, M. E. Trends Biotechnol. 1992, 10, 132.

5. Gee, J. E.; Miller, D. M. Am. J. Med. Sci. 1992, 304, 366.

6. Hélène, C. Anti-cancer Drug Des. 1991, 6, 569.

7. Wells, R. D. J. Biol. Chem. 1996, 271, 2875.

8. Mitas, M. Nucleic Acids Res. 1997, 25, 2245.

9. Richards, R. I.; Sutherland, G. R. Cell 1992, 70, 709.

10. Sinden, R. R.; Wells, R. D. Curr. Opin. Biotechnol. 1992, 3, 612.

11. Pearson, C. E.; Sinden, R. R. Curr. Opin. Struct. Biol. 1998, 8, 321.

12. Ashley, C. T., Jr; Warren, S. T. Annu. Rev. Genet. 1995, $29,703$.

13. de los Santos, C.; Rosen, M.; Patel, D. Biochemistry 1989, 28, 7282.

14. Rajagopal, P.; Feigon, J. Nature 1989, 339, 637.

15. Rajagopal, P.; Feigon, J. Biochemistry 1989, 28, 7859.

16. Weiner, A. M. Cell 1988, 52, 155.

17. Sijbesma, R. P.; Meijer, E. W. Chem. Commun. 2003, 5.

18. (a) Sindona, G.; Uccella, N.; Weclawek, K. J. Chem. Res. Suppl. 1982, 184. (b) Panico, M.; Sindona, G.; Uccella, N. J. Am. Chem. 
Soc. 1983, 105, 5607. (c) Beckey, H. D.; Levsen, K.; Roellgen, F. W.; Schulten, H. R. Surf. Sci. 1978, 70, 325.

19. Fenn, J. B.; Mann, M.; Meng, C. K.; Whitehouse, C. M. Science 1989, 246, 64 .

20. Koch, K. J.; Aggerholm, T.; Nanita, S. C.; Cooks, R. G. J. Mass Spectrom. 2002, 37, 676.

21. Cooks, R. G.; Patrick, J. S.; Kotiaho, T.; McLuckey, S. A. Mass Spectrom. Rev. 1994, 13, 287.

22. (a) Greco, F.; Liguori, A.; Sindona, G.; Uccella, N. J. Am. Chem. Soc. 1990, 112, 9092. (b) Liguori, A.; Napoli, A.; Sindona, G. Rapid Commun. Mass Spectrom. 1994, 8, 89.

23. Di Donna, L.; Napoli, A.; Siciliano, C.; Sindona, G. Int. J. Mass Spectrom. 2001, 210/211, 165-172.

24. Liguori, A.; Napoli, A.; Sindona, G. J. Mass Spectrom. 2000, 35, 139.

25. Hunter, E. P. L.; Lias, S. G. J. Phys. Chem. Ref. Data 1988, 27.

26. Dill, J. D.; Allen, L. C.; Topp, W. C.; Pople, J. A. J. Am. Chem. Soc. 1975, 97, 7220 .

27. Jorgensen, W. L.; Gao, J. J. Phys. Chem. 1986, 90, 2174.

28. Gao, J.; Garner, D. S.; Jorgensen, W. L. J. Am. Chem. Soc. 1986, 108,4784

29. Frisch, M. J.; Trucks, G. W.; Schlegel, H. B.; Scuseria, G. E.; Robb, M. A.; Cheeseman, J. R.; Zakrzewski, V. G.; Montgomery, J. A., Jr; Stratmann, R. E.; Burant, J. C.; Dapprich, S.; Millam, J. M.; Daniels, A. D.; Kudin, K. N.; Strain, M. C.; Farkas, O.; Tomasi, J.; Barone, V.; Cossi, M.; Cammi, R.; Mennucci, B.; Pomelli, C.; Adamo, C.; Clifford, S.; Ochterski, J.; Petersson, G. A.; Ayala, P. Y.; Cui, Q.; Morokuma, K.; Rega, N.; Salvador, P.; Dannenberg, J. J.; Malick, D. K.; Rabuck, A. D.; Raghavachari, K.; Foresman, J. B.; Cioslowski, J.; Ortiz, J. V.; Baboul, A. G.; Stefanov, B. B.; Liu, G.; Liashenko, A.; Piskorz, P.; Komaromi, I.; Gomperts, R.; Martin, R. L.; Fox, D. J.; Keith, T.; Al-Laham, M. A.; Peng, C. Y.; Nanayakkara, A.; Challacombe, M.; Gill, P. M. W.; Johnson, B.; Chen, W.; Wong, M. W.; Andres, J. L.; Gonzalez, C.; Head-
Gordon, M.; Replogle, E. S.; Pople, J. A. Gaussian 98, Rev. A.11.3; Gaussian, Inc: Pittsburgh, PA, 2002.

30. North, A. C. T.; Philips, D. C.; Mathews, F. S. Acta Crystallogr. A 1968, 24, 351.

31. SHELXTL NT, Version 5.10; Bruker Analytical X-ray Instruments Inc.: Madison, WI, 1998.

32. Nardelli, M. Comput. Chem. 1983, 7, 95.

33. Schimanski, A.; Freisinger, E.; Erxleben, A.; Lippert, B. Inorg. Chim. Acta 1998, 283, 223 and references cited therein.

34. De Nino, A.; Mazzotti, F.; Perri, E.; Procopio, A.; Raffaelli, A.; Sindona, G. J. Mass Spectrom. 2000, 35, 461.

35. Di Donna, L.; Napoli, A.; Sindona, G. In Advances in Mass Spectrometry Vol XV; Gelpi, E., Ed.; John Wiley and Sons, Ltd.: Chichester, England 2001; pp 765-766.

36. Armentrout, P. B. J. Am. Chem. Soc. Mass Spectrom. 2000, 11, 371.

37. Marsh, R. E.; Bierstedt, R.; Eichhorn, E. L. Acta Crystallogr. 1962, 15, 310.

38. Fujinami, F.; Ogawa, K.; Arakawa, Y.; Shirotake, S.; Fujii, S.; Tomita, K. Acta Crystallogr. B 1979, 35, 968.

39. Chen, L.; Cai, L.; Zhang, X.; Rich, A. Biochemistry 1994, 33, 13540.

40. Salam, M. D.; Aoki, K. Inorg. Chim. Acta 2000, 311, 15.

41. (a) Kistenmacher, T. J.; Rossi, M.; Marzilli, L. G. Biopolymers 1978, 17, 2581. (b) Kistenmacher, T. J.; Rossi, M.; Caradonna, J. P.; Marzilli, L. G. Adv. Mol. Relaxation Interact. Processes 1979, 15, 119. (c) Kistenmacher, T. J.; Rossi, M.; Chiang, C. C.; Caradonna, J. P.; Marzilli, L. G. Adv. Mol. Relaxation Interact. Processes 1980, 17, 113.

42. Shaw, B. R.; Williams, N. G.; Williams, L. D. J. Am. Chem. Soc. 1989, 111, 7205.

43. Beijer, F. H.; Sijbesma, R. P.; Vekemans, J. A. J. M.; Meijer, E. W.; Kooijman, H.; Speck, A. L. J. Org. Chem. 1996, 61, 6371.

44. Izatt, R. M.; Christensen, J. J.; Rytting, J. H. Chem. Rev. 1971, 71, 439. 